\title{
Bazı EIma (Malus domestica L.) Çeşitlerinin Fenolojik ve Pomolojik Özelliklerinin Belirlenmesi
}

\author{
Selma BOYACI* \\ Kırşehir Ahi Evran Üniversitesi, Ziraat Fakültesi, Bahçe Bitkileri Bölümü, Kırșehir, TÜRKIYYE
}

\begin{tabular}{|c|c|}
\hline Geliş Tarihi/Received: 06.11 .2018 & Kabul Tarihi/Accepted: 23.02 .2019 \\
\hline \multicolumn{2}{|l|}{ ORCID ID } \\
\hline (1D) orcid.org/0000-0002-3349-839X & \\
\hline
\end{tabular}

Öz: Bu çalışma; MM.106 yarı bodur elma anacı üzerine aşılı Mondial Gala, Red Chief, Golden Delicious, Braeburn ve Granny Smith elma çeșitlerinin fenolojik gözlem ve pomolojik özellikleri dikkate alınarak, Kırșehir koşullarında performanslarının belirlenmesi amacıyla, 2017-2018 yıllarında yürütülmüştür. Çalışmada, fenolojik gözlemler olarak; tomurcuk kabarması, tomurcuk patlaması, ilk çiçeklenme, tam çiçeklenme ve çiçeklenme sonu tarihleri ile hasat tarihleri belirlenmiştir. Pomolojik özellikler olarak ise; meyve ağırlı̆̆ $(\mathrm{g})$, meyve eni ve boyu (mm), suda çözünür kuru madde miktarı (SÇKM), meyve eti sertliği $\left(\mathrm{kg} \mathrm{cm}^{-2}\right), \mathrm{pH}$, tohum sayısı (adet) ve tohum ağırlı ̆̆ $(\mathrm{g})$, meyvenin sap uzunluğu ve kalınlı̆̆ $(\mathrm{mm})$ ve renk değerleri belirlenmiştir. Fenolojik gözlemlerde; 2018 yılında çiçek tomurcuklarının 2017 yılına göre 1 hafta kadar daha erken uyandığı tespit edilmiștir. İncelenen ceșitlerde; meyve ağırlı̆̆ı, 163.31-215.00 g, meyve eni 71.10-77.33 mm, meyve boyu 63.20-71.26 $\mathrm{mm}$, SÇKM \% 11.16-15.41, meyve eti sertliği 4.72-6.14 kg cm${ }^{-2}, \mathrm{pH} 3.31-4.03$, tohum sayısı 6.75-9.35 adet, tohum ağırlığ 0.35-0.59 g, meyve sap uzunluğu 24.80-35.87 mm, meyve sap kalınlığ 1.79-2.74 mm, meyve üst zemin rengi L değeri 19.5078.86, a değeri -21.01-43.24, b değeri 10.10-51.24 arasında değişmiștir. Fenolojik gözlem ve pomolojik özellikler dikkate alındığında, üzerinde çalışılan Mondial Gala, Red Chief, Golden Delicious, Braeburn ve Granny Smith elma çeşitlerinin Kırşehir ekolojik koşullarına uygun olduğu kanaatine varılmışır.

Anahtar Kelimeler: Kırşehir, elma, fenolojik gözlemler, pomolojik özellikler, suda çözünür kuru madde

\section{Determination of Phenological and Pomological Characteristics of Some Apple (Malus domestica L.) Cultivars}

\begin{abstract}
This study was carried out in 2017-2018 with the aim of determining the performances of Mondial Gala, Red Chief, Golden Delicious, Braeburn and Granny Smith apple varieties grafted on MM.106 semi-dwarf apple rootstock, by taking phenological observation and pomological characteristics into account, under Kırşehir conditions. In the study, harvest dates with bud blossom, bud burst, first flowering, full bloom and end of flowering were determined as phenological observations. Pomological characteristics, fruit weight (g), fruit width and length (mm), soluble solids content (TSSC), fruit flesh firmness $\left(\mathrm{kg} \mathrm{cm}^{-2}\right), \mathrm{pH}$, number of seeds (pieces) and seed weight $(\mathrm{g})$, fruit stalk length and thickness $(\mathrm{mm})$ and color values were determined. Phenological observations; In 2018 flower buds were awakened 1 week earlier than in 2017. Fruit weight in the examined varieties, 163.31-215.00 g, fruit width 71.10-77.33 mm, fruit size 63.20-71.26 mm, soluble solids content (TSSC) $11.16 \%-15.41 \%$, fruit flesh firmness $4.72-6.14 \mathrm{~kg} \mathrm{~cm}^{-2}, \mathrm{pH} 3.31-4.03$, number of seeds 6.75-9.35 pcs, seed weight 0.35-0.59 $\mathrm{g}$, fruit stalk length $24.80-35.87 \mathrm{~mm}$, fruit stalk thickness 1.79-2.74 mm, fruit skin color $\mathrm{L}$ value 19.50-78.86, a value -21.0143.24, and $\mathrm{b}$ value was changed between 10.10-51.24. Considering the phenological observations and pomological characteristics, it is concluded that apple varieties such as Mondial Gala, Red Chief, Golden Delicious, Braeburn and Granny Smith are suitable for Kırșehir ecological conditions.
\end{abstract}

Keywords: Kırșehir, apple, phenological observations, pomological characteristics, soluble solids content 


\section{Giriş}

Botanik olarak elma (Malus domestica L.); Dicotiledoneae sınıfi, Rosaceae familyası ve Malus cinsinden yer almaktadır. Dünya üzerinde Asya, Avrupa ve Kuzey Amerika'da doğal olarak yetişen 30 kadar elma türü bulunmaktadır (Özçağıran ve ark., 2011).

Bahçe bitkileri yetiştiriciliği içerisinde önemli bir yere sahip olan elma, iki bin yıldan fazla dünyada en çok tüketilen meyvelerden birisi haline gelmiştir. Tarımsal açıdan Türkiye, sahip olduğu coğrafi ve ekolojik koşullar nedeniyle, farklı iklim ve toprak isteği olan birçok meyve türünün bir arada yetiştirildiği ender ülkelerden birisidir. Türkiye'de yetişme alanı bakımından üzümden sonra 2. sırada yer alan elma, hemen hemen bütün bölgelerde yetiştiriciliği yapılan önemli bir türdür. Elmanın anavatanlarından biri olan ve elma yetiştiriciliğinde önemli bir konuma sahip olan Türkiye, son 50 yıl içerisinde elma üretimini en az 20 kat arttırarak, üretim miktarı bakımından 3.032.164 ton ile Çin'den sonra dünyada ikinci sırada yer almaktadır (Anonymous, 2018a). Son yıllarda Türkiye'de elma üretimi kayda değer bir artış göstermesine rağmen, ihracat miktarının ve dolayısıyla gelirinin düşük seviyelerde olmasının sebeplerinden biri de elmada kalite standartlarının yakalanamamasıdır (Uzundumlu ve ark., 2009).

Dünyada 10.000, Türkiye'de ise yaklaşı 500600 elma çeşidi bulunmaktadır (Özçağıran ve ark., 2011). Farklı elma çeşitlerinde kaliteli elma yetiştiriciliği için fenolojik gözlem ve pomolojik özellikler dikkate alınarak, bölgesel performanslarının belirlenmesi amacıyla Türkiye'de ve dünyada yapılmış çok sayıda çalışma bulunmaktadır (Akça ve Şen, 1991; Ishiykawa ve ark., 1991; Şen ve ark., 1992; Oğuz ve Aşkın, 1993; Bongers ve ark., 1994; Burak ve ark., 1995; Balta ve Uca, 1996; Alumur, 1997; Mataa, 2000; Tustin ve ark., 2001; Fischer ve Fischer, 2002; Warmund, 2004; Blazec ve Krelinova, 2006; Seferoğlu ve ark., 2006; Acar, 2007; Şen, 2008; Kazankaya ve ark., 2009; Dousti, 2010; Baytekin ve Akça, 2011;
Doğru, 2012, Özongun ve ark., 2014; Balta ve ark., 2015; Güneş, 2017).

Bu çalışmada, MM.106 yarı bodur elma anacı üzerine aşılı bazı elma çeşitlerinin fenolojik ve pomolojik özellikleri dikkate alınarak Kırşehir koşullarında performanslarının belirlenmesi amaçlanmıştır.

\section{Materyal ve Yöntem}

Çalıșma; Kırșehir'de özel bir üreticiye ait elma bahçesinde bulunan MM.106 yarı bodur elma anacı üzerine aşılı Mondial Gala, Red Chief, Golden Delicious, Braeburn ve Granny Smith elma çeşitleri üzerinde 2017-2018 y1llarında yürütülmüştür. Araştırma, 4 x 4 m sıra üzeri ve arası mesafelerle 2007 yılında tesis edilen söz konusu bahçede, tesadüf parselleri deneme desenine göre 3 tekerrürlü olarak yürütülmüş ve çalışmada her tekerrürde 5 ağaca yer verilmiştir. Çalışmada, tüm bakım işlemleri (sulama, gübreleme, budama ve ilaçlama gibi) düzenli olarak yapılmıştır. Kırşehir ilinin uzun yıllar ve araştırma yıllarına ait sıcaklık ve nem değerleri Tablo 1'de verilmiştir.

Araştırmada, fenolojik gözlemler olarak; tomurcuk kabarması, tomurcuk patlaması, ilk çiçeklenme, tam çiçeklenme ve çiçeklenme sonu tarihleri ile hasat tarihleri Hampson ve Kemp (2003)'e göre belirlenmiştir. Pomolojik özellikler olarak ise, çeşitlerden rastgele seçilen 20 'şer adet meyve üzerinde; meyve ağırlığı (g), meyve eni ve boyu (mm), suda çözünür kuru madde miktarı (SÇKM), meyve eti sertliği $\left(\mathrm{kg} \mathrm{cm}^{-2}\right), \mathrm{pH}$, tohum sayısı (adet) ve tohum ağırlığı (g), meyvenin sap uzunluğu ve kalınlığı $(\mathrm{mm})$ ve renk değerleri [L: Parlaklık, a: Yeşil renkten (-) kırmızı renge $(+)$ geçiş, b: Mavi renkten (-) sarı renge $(+)$ geçiş] McGuire (1992)'e göre belirlenmiştir.

Çalışma sonunda elde edilen veriler, tesadüf parselleri deneme desenine göre SPSS 22.0 istatistiksel paket programı ile varyans analizleri yapılmış; ortalamalar arasındaki farklılıklar, Duncan çoklu karşılaştırma testi ile kontrol edilmiştir (Yurtsever, 1984).

Tablo 1. Kırşehir ilinin uzun yıllar ve çalışma yıllarına ait sıcaklık ve nem değerleri

\begin{tabular}{|c|c|c|c|c|c|c|c|c|c|c|c|c|c|c|}
\hline \multirow{2}{*}{ Yillar } & \multirow{2}{*}{ Parametreler } & \multicolumn{12}{|c|}{ Aylar } & \multirow{2}{*}{ Ort. } \\
\hline & & 1 & 2 & 3 & 4 & 5 & 6 & 7 & 8 & 9 & 10 & 11 & 12 & \\
\hline \multirow{2}{*}{$\begin{array}{l}1960- \\
2018\end{array}$} & Sicaklık $\left({ }^{\circ} \mathrm{C}\right)$ & -0.2 & 1.3 & 5.5 & 10.7 & 15.3 & 19.5 & 23.0 & 23.0 & 18.5 & 12.7 & 6.4 & 1.9 & 11.5 \\
\hline & Nispi nem $(\%)$ & 78.6 & 74.6 & 67.9 & 63.8 & 61.4 & 55.1 & 48.4 & 48.5 & 52.7 & 63.4 & 72.6 & 79.2 & 63.9 \\
\hline \multirow{2}{*}{2017} & Sicaklık $\left({ }^{\circ} \mathrm{C}\right)$ & -2.4 & 1.0 & 7.3 & 10.7 & 15.2 & 20.7 & 26.0 & 25.6 & 23.1 & 12.4 & 6.3 & 4.4 & 12.5 \\
\hline & Nispi nem (\%) & 77.9 & 67.0 & 60.8 & 52.4 & 59.4 & 54.3 & 36.0 & 43.2 & 31.7 & 53.0 & 71.6 & 77.2 & 57.0 \\
\hline \multirow{2}{*}{2018} & Sicaklık $\left({ }^{\circ} \mathrm{C}\right)$ & 2.1 & 6.5 & 9.7 & 14.0 & 17.3 & 21.5 & 25.2 & 25.1 & 20.2 & 14.4 & 8.2 & 3.3 & 14.0 \\
\hline & Nispi nem (\%) & 81.7 & 68.6 & 66.2 & 49.1 & 64.8 & 53.4 & 43.0 & 39.2 & 45.7 & 62.3 & 66.8 & 81.4 & 60.2 \\
\hline
\end{tabular}

Ort.: Ortalama 


\section{Bulgular ve Tartışma}

\subsection{Fenolojik gözlemler}

Mondial Gala, Red Chief, Golden Delicious, Braeburn ve Granny Smith elma çeşitlerinin 2017 ve 2018 yıllarına ait fenolojik gözlem tarihleri Tablo 2'de verilmiştir.

Fenolojik gözlem açısından her iki yıl değerlendirildiğinde; 2018 yılında tomurcukların
2017 yılına göre yaklaşık 1 hafta kadar daha erken uyandığ 1 görülmüştür (Tablo 2). Her iki yılda da en erken tomurcuk uyanma tarihi Mondial Gala çeşidinde (04.04.2017-30.03.2018), en geç tomurcuk uyanma tarihi Granny Smith çeşidinde (19.04.2017-14.04.2018) görülmüştür (Tablo 2). Benzer şekilde Ankara ilinde Dousti (2010) tarafından yürütülen bir çalışmada; Braeburn, Fuji, Gala, Granny Smith, Jonagold ve Top Red

Tablo 2. Mondial Gala, Red Chief, Golden Delicious, Braeburn ve Granny Smith elma çeşitlerinin 2017-2018 yıllarına ait fenolojik gözlem tarihleri

\begin{tabular}{lccccc}
\hline Fenolojik gözlem & Mondial Gala & Red Chief & Golden Delicious & Brebaurn & Granny Smith \\
\hline Tomurcuk uyanmas1 & $04.04 / 30.03$ & $08.04 / 03.04$ & $13.04 / 09.04$ & $18.04 / 11.04$ & $19.04 / 14.04$ \\
İlk çiçeklenme & $12.04 / 07.04$ & $17.04 / 10.04$ & $21.04 / 13.04$ & $25.04 / 18.04$ & $25.04 / 20.04$ \\
Tam çiçeklenme & $19.04 / 12.04$ & $22.04 / 16.04$ & $25.04 / 19.04$ & $30.04 / 22.04$ & $02.05 / 25.04$ \\
Çiçeklenme sonu & $27.04 / 20.04$ & $30.04 / 22.04$ & $05.05 / 25.04$ & $10.05 / 01.05$ & $12.05 / 04.05$ \\
Hasat Tarihi & $04.09 / 31.08$ & $15.09 / 05.09$ & $18.09 / 08.09$ & $15.10 / 29.09$ & $20.10 / 08.10$ \\
\hline
\end{tabular}

çeşitlerinde, çiçeklenme başlangıcı tarihlerinin 2008 yılında 2009 yılına göre daha erken başladığını, 2008 yılında bir sonraki yıla göre çiçeklenmenin yaklaşık 1 hafta daha önce olduğunu bildirmiştir. Konya ilinde Arıkan ve ark. (2015) tarafından yürütülen çalışmada, Summer Red, Jersey Mac, Red Chief, Braeburn, Jonagold, Golden Delicious ve Fuji elma çeşitlerinde tam çiçeklenmenin 5 Mayıs-19 Mayıs tarihleri arasında gerçekleştiğini; Baytekin ve Akça (2011) tarafindan Turhal (Tokat) koşullarında yürütülen bir çalışmada da Granny Smith, Stark Spur Golden ve Red Chief elma çeşitlerinin çiçeklenme tarihi başlangıcı 16 Nisan (Granny Smith)-21 Nisan (Red Chief) olarak belirlendiğini bildirmişlerdir. Legave ve ark. (2008) bitki fenolojisinin temel olarak sicaklıktan etkilendiğini ve fenolojik gözlemlerin önem kazandığını; meyve ağaçlarının, çiçeklenme fenolojisi zamanlamasındaki değişikliklerin, don zararı, tozlanma ve meyvenin verimi üzerindeki dolaylı etkileri nedeniyle meyve üretimi üzerinde önemli etkilere neden olabildiğini bildirmişlerdir. Ayrıca Soylu ve ark. (2003), çiçeklenme tarihlerinin iklim koşullarından etkilendiğini, çeşitlere ve yıllara göre farklılık gösterdiğini bildirmişlerdir. Nitekim ilin sıcaklık değerleri incelendiğinde de; 2017 y1lı Mart ay1 ortalama sıcaklık değeri $7.3{ }^{\circ} \mathrm{C}$ iken, 2018 y1lı Mart ay1 ortalama sicaklık değeri $9.7 \quad{ }^{\circ} \mathrm{C}$ olarak gerçekleşmiştir (Tablo 1). Çalışmada, 2018 yılındaki ortalama sıcaklık değerlerinin 2017 yılına göre daha yüksek olması, çeşitlerde erken tomurcuk uyanmasını teşvik etmiştir.

Hasat tarihleri değerlendirildiğinde, her iki yılda en erken hasat tarihi 4 Eylül-31 Ağustos Mondial Gala çeşidinde, en geç hasat ise 20 Ekim-8 Ekim tarihinde Granny Smith çeşidinde gerçekleşmiştir. Ayrıca çalışmada incelenen çeşitlerin fenolojik gözlemleri bölge ekolojik koşullarına göre değişmekle birlikte, genel olarak daha önceki araştırmacılar (Seferoğlu ve ark., 2006; Şen, 2008; Çulha, 2010; Öztürk ve Öztürk, 2016) tarafından yapılan gözlemlerle uyumlu bulunmuştur.

\subsection{Pomolojik özellikler}

Mondial Gala, Red Chief, Golden Delicious, Braeburn ve Granny Smith elma çeşitlerinin 2017 ve 2018 y1llarına ait ortalama pomolojik analiz sonuçları Tablo 3 'te verilmiştir.

Tablo 3'ten görüldüğü üzere, meyve kalite kriterlerinin en önemlilerinden biri olan meyve ağırlı̆̆ı; çeşitler arasında en fazla istatistiki olarak birinci grubu oluşturan Red Chief $(215.00 \mathrm{~g})$ ve Mondial Gala (209.16 g) çeşidinde, en az ise 163.31-168.08 g arasında değișen miktarlara sahip Braeburn, Golden Delicious ve Granny Smith çeşidinde rastlanmıştır. Meyve ağırlığı yönünden ele alınan çeşitler arasındaki bu farklılık istatistiki yönden $\mathrm{p}<0.01$ düzeyinde önemli bulunmuştur (Tablo 3). Baytekin (2006) tarafından Tokat koşullarında yapılan bir çalışmada, ortalama meyve ağırlıklarını Granny Smith, Amasya, Golden Delicious ve Starking Delicious çeşitlerinde, sirasiyla; 213.89 g, 167.55 g, 190.17 g ve 190.56 g olarak tespit etmiştir. Çulha (2010) tarafından Granny Smith, Fuji, Golden Delicious, Starking Delicious ve Red Chief çeşitleri ile yapılan çalıșmada, en fazla meyve ağırlığının Red Chief (205.51 g) çeşidinden elde edildiği bildirilmiştir. Çalışmamızda çeşitlerin meyve ağırlığ sonuçlarıyla literatür bulguları kısmen uyumlu görülmektedir. Aradaki bu farklılıkların iklim, 
Tablo 3. Mondial Gala, Red Chief, Golden Delicious, Braeburn ve Granny Smith elma çeşitlerinin 2017-2018 yıllarına ait pomolojik analiz sonuçları ${ }^{1}$

\begin{tabular}{lccccc}
\hline Pomolojik özellikler & Mondial Gala & Red Chief & Golden Delicious & Braeburn & Granny Smith \\
\hline Meyve ağırlığı $(\mathrm{g})$ & $209.16 \pm 7.68 \mathrm{a}$ & $215.00 \pm 11.84 \mathrm{a}$ & $163.89 \pm 4.97 \mathrm{~b}$ & $163.31 \pm 3.56 \mathrm{~b}$ & $168.08 \pm 5.05 \mathrm{~b}$ \\
Meyve eni $(\mathrm{mm})$ & $76.87 \pm 0.70 \mathrm{a}$ & $77.33 \pm 1.35 \mathrm{a}$ & $71.10 \pm 0.82 \mathrm{~b}$ & $71.46 \pm 1.02 \mathrm{~b}$ & $72.89 \pm 0.75 \mathrm{~b}$ \\
Meyve boyu $(\mathrm{mm})$ & $65.82 \pm 1.01 \mathrm{~b}$ & $71.26 \pm 2.00 \mathrm{a}$ & $65.88 \pm 0.95 \mathrm{~b}$ & $63.85 \pm 1.20 \mathrm{~b}$ & $63.20 \pm 0.91 \mathrm{~b}$ \\
SÇKM (\%) & $15.41 \pm 0.07 \mathrm{a}$ & $11.53 \pm 0.07 \mathrm{~d}$ & $13.06 \pm 0.28 \mathrm{c}$ & $14.64 \pm 0.08 \mathrm{~b}$ & $11.16 \pm 0.07 \mathrm{~d}$ \\
Meyve eti sertliği $\left(\mathrm{kg} \mathrm{cm}^{-2}\right)$ & $5.44 \pm 0.10 \mathrm{~b}$ & $4.72 \pm 0.10 \mathrm{c}$ & $4.97 \pm 0.77 \mathrm{c}$ & $6.14 \pm 0.11 \mathrm{a}$ & $5.90 \pm 0.10 \mathrm{a}$ \\
pH & $3.54 \pm 0.01 \mathrm{c}$ & $4.03 \pm 0.01 \mathrm{a}$ & $3.64 \pm 0.02 \mathrm{~b}$ & $3.53 \pm 0.02 \mathrm{c}$ & $3.31 \pm 0.01 \mathrm{~d}$ \\
Tohum sayısı (adet) & $7.35 \pm 0.38 \mathrm{~b}$ & $6.75 \pm 0.40 \mathrm{~b}$ & $8.75 \pm 0.15 \mathrm{a}$ & $9.00 \pm 0.49 \mathrm{a}$ & $9.35 \pm 0.33 \mathrm{a}$ \\
Tohum ağırlığ1 (g) & $0.37 \pm 0.02 \mathrm{c}$ & $0.35 \pm 0.02 \mathrm{c}$ & $0.50 \pm 0.01 \mathrm{~b}$ & $0.59 \pm 0.02 \mathrm{a}$ & $0.55 \pm 0.01 \mathrm{ab}$ \\
Meyve sap uzunluğu (mm) & $28.75 \pm 0.93 \mathrm{~b}$ & $27.49 \pm 0.59 \mathrm{bc}$ & $35.87 \pm 0.87 \mathrm{a}$ & $24.80 \pm 0.63 \mathrm{~d}$ & $26.24 \pm 0.55 \mathrm{~cd}$ \\
Meyve sap kalınlığı (mm) & $2.31 \pm 0.10 \mathrm{~b}$ & $2.74 \pm 0.08 \mathrm{a}$ & $1.79 \pm 0.05 \mathrm{c}$ & $2.35 \pm 0.09 \mathrm{~b}$ & $2.14 \pm 0.07 \mathrm{~b}$ \\
Meyve üst renk L & $35.94 \pm 1.11 \mathrm{c}$ & $19.50 \pm 1.27 \mathrm{~d}$ & $78.86 \pm 1.78 \mathrm{a}$ & $32.69 \pm 2.27 \mathrm{c}$ & $49.08 \pm 1.95 \mathrm{~b}$ \\
Meyve üst renk a & $35.80 \pm 3.27 \mathrm{~b}$ & $26.64 \pm 1.37 \mathrm{c}$ & $-21.01 \pm 1.45 \mathrm{~d}$ & $43.24 \pm 2.06 \mathrm{a}$ & $-23.25 \pm 0.62 \mathrm{~d}$ \\
Meyve üst renk b & $22.30 \pm 0.84 \mathrm{c}$ & $10.10 \pm 0.94 \mathrm{~d}$ & $51.24 \pm 1.42 \mathrm{a}$ & $21.63 \pm 1.29 \mathrm{c}$ & $31.01 \pm 1.28 \mathrm{~b}$ \\
\hline
\end{tabular}

1: Aynı satırda farklı harfler arasındaki değerler p<0.01 düzeyinde önemlidir, L: Parlaklık, a: Yeşil renkten (-) kırmızı renge (+) geçiş, b: Mavi renkten $(-)$ sarı renge $(+)$ geçiş

çeşit-anaç ve bakım işlemleri ile ilgili olduğu kanaatine varılmıştır.

Meyve eni yönünden en yüksek değer Red Chief $(77.33 \mathrm{~mm})$ ve Mondial Gala $(76.87 \mathrm{~mm})$ çeşitlerinde; meyve boyu açısından ise en yüksek değer Red Chief (71.26 mm) çeşidinde belirlenmiş; meyve eni ve boyu yönünden diğer çeşitler ise düşük grupta yer almışlardır. Her iki özellik yönünden çeşitler arasındaki bu farklılık istatistiki yönden $\mathrm{p}<0.01$ düzeyinde önemli bulunmuştur (Tablo 3). Hicyakmazer (1996), Pozant1 koşullarında yürütmüş olduğu çalışmasında, Golden Delicious, Starking Delicious ve Granny Smith elma çeşitlerinde meyve eni ve boyu değerlerini sırasılya; $51.80 \mathrm{~mm}$ ve $50.40 \mathrm{~mm}, 68.20$ $\mathrm{mm}$ ve $65.50 \mathrm{~mm}, 65.80 \mathrm{~mm}$ ve $61.70 \mathrm{~mm}$ olarak belirlemiştir. Ceylan (2008), Konya şartlarında; meyve en ve meyve boy değerleri bakımından Granny Smith (75.86 mm ve $66.68 \mathrm{~mm}$ ) ve Fuji (75.25 mm ve $63.07 \mathrm{~mm}$ ) çeşitlerinin ilk sırada yer aldığını, bu çeşitleri Red Chief (74.34 mm ve 64.24 $\mathrm{mm})$ çeşidinin izlediğini bildirmiştir. Çalışmadan elde edilen sonuçlarla literatür bulguları uyumlu bulunmuştur. Bununla birlikte, Türk Standartları Enstitüsü (TSE) tarafindan elmalar, kalite özelliklerine göre; ekstra, I. sınıf, II. sınıf olmak üzere üç sınıfa ayrılmaktadır. Buna göre elmalarda, sinıflara göre kabul edilen en küçük çap ölçü değerleri alınarak; 65 mm üstündekiler ekstra, 60$65 \mathrm{~mm}$ arası I. sinıf, 55-60 mm arasi II. sinıf olarak belirlenmiştir (Anonim, 2018). Tablo 3'den de görüleceği üzere, her ne kadar incelenen çeşitler arasındaki fark anlamlı olsa da, üzerinde çalışılan tüm çeşitlerin (Mondial Gala, $76.87 \mathrm{~mm}$; Red Chief, 77.33 mm; Golden Delicious, $71.10 \mathrm{~mm}$; Braeburn, 71.46 mm; Granny Smith, $72.89 \mathrm{~mm}$ ), TSE tarafindan bildirilen sinıflamaya göre ekstra sınıfına dâhil olduğu görülmüştür.
Suda çözünür kuru madde miktarı (SÇKM) bakımından çeşitlerde en yüksek değer \% 15.41 ile Mondial Gala çeşidinde, en düşük değer ise \% 11.16 ile Granny Smith ve \% 11.53 ile Red Chief çeşidinde bulunmuştur (Tablo 3). Karlıdağ ve Eşitken (2006) Erzurum şartlarında yürüttükleri çalışmalarında üzerinde çalıştıkları elma çeşitlerinde SÇKM değerlerinin \% 9.10-13.80; Öztürk ve Öztürk (2016) ise SÇKM değerlerinin \% 10.46-13.45 arasında olduğunu tespit etmişlerdir. Elmada meyve kalitesi bakımından suda çözünür kuru madde miktarının yaklaşık \% 11 olması istenmektedir (Gulino, 1986). Üzerinde çalışılan tüm çeşitlerde (Mondial Gala, \% 15.41; Red Chief, $\%$ 11.53; Golden Delicious, \% 13.06; Braeburn, \% 14.64; Granny Smith, \% 11.16), SÇKM miktarı bu oranın üzerinde olduğu tespit edilmiş olup, SÇKM içeriklerinin yeterli olduğu kanaatine varılmıştır.

Meyve eti sertliği bakımından en yüksek değere Braeburn ve Granny Smith çeşitlerinde (sırasıyla, $6.14 \mathrm{~kg} \mathrm{~cm}^{-2}$ ve $5.90 \mathrm{~kg} \mathrm{~cm}^{-2}$ ) rastlanırken, en düşük değer Red Chief (4.72 $\mathrm{kg} \mathrm{cm}^{-2}$ ) ve Golden Delicious (4.97 kg cm${ }^{-2}$ ) çeşitlerinde bulunmuştur (Tablo 3). Benzer şekilde Arıkan ve ark. (2015) tarafindan Summer Red, Jersey Mac, Red Chief, Braeburn, Jonagold, Golden Delicious ve Fuji çeşitlerinde yapmış oldukları çalışmada da meyve eti sertliği yönünden en yüksek değere Braeburn çeşidinde (5.92 $\mathrm{kg} \mathrm{cm}^{-2}$ ) rastlanıldığını bildirmişlerdir. Bir başka çalışmada Kaynaş ve Karaçalı (1990), Yalova koşullarında Granny Smith elma çeşidinde meyve eti sertliğini $7.5-8 \mathrm{~kg} \mathrm{~cm}^{-2}$ olarak tespit etmişlerdir. Çalışmamızla, diğer yapılan çalışmalar arasında meyve eti sertliği bakımından farklılıklar bulunmaktadır. Bu farklılıklar Özçağıran ve ark. (2011) tarafından da belirtildiği üzere; olgunluk dönemine, bölgelerin iklim koşullarına, kültürel işlemlere, yıllara ve çeşide göre değişiklik 
göstermesi ile açıklanabilir. Ayrıca, Deell ve ark. (2001), meyve eti sertliğinin hasat öncesi ve hasat sonrası dönem olmak üzere birçok faktörden etkilendiğini; özellikle hasat öncesi dönemde bitkinin genetik yapısının, bitkinin beslenme durumunun, kültürel uygulamaların ve bitki büyüme düzenleyicilerin önemli rol oynadığını bildirmişlerdir. Bitki Genetik Kaynakları Uluslararası Kurulunun (IBPGR) elmalar için belirlediği elma tanımlayıcısı (Apple descriptors) özellikler çizelgesine göre (Anonymous, 2018b), elma çeşitlerinde olması gereken meyve eti sertliği kategorisinde; üzerinde çalışılan çeşitler (Mondial Gala, 5.44; Red Chief, 4.72; Golden Delicious, 4.97; Braeburn, 6.14; Granny Smith, 5.90) “ekstra sert-5 $\mathrm{kg} \mathrm{cm}^{-2}$ " sınıfina dâhil olmuştur.

Tablo 3 incelendiğinde; en yüksek pH değerine 4.03 ile Red Chief çeşidinde rastlanırken, en düşük pH değeri 3.31 ile Granny Smith çeşidinde bulunmuştur. Arıkan ve ark. (2015) tarafindan Summer Red, Jersey Mac, Red Chief, Braeburn, Jonagold, Golden Delicious ve Fuji çeşitlerinde yapılan çalışmada, pH değerlerinin 3.43 (Jersey Mac) ile 4.30 (Red Chief) arasında bulunduğunu bildirmişlerdir. Şenyurt ve ark. (2015) üzerinde çalıştıkları elma çeşitlerinde, $\mathrm{pH}$ değerlerini 3.50 (Ekşi-1) ile 4.87 (Amasya) arasında değiştiğini bildirmişlerdir. Çalışmamızda elde edilen $\mathrm{pH}$ değerleri diğer çalışmalarla benzerlik göstermektedir.

Çalışmada ele alınan elma çeşitlerinde tohum sayılar1 6.75 adet (Red Chief) ile 9.35 adet (Granny Smith) arasındadır (Tablo 3). Tohum ağırlıkları ise $0.35 \mathrm{~g}$ (Red Chief) ile $0.59 \mathrm{~g}$ (Braeburn) arasında değişim göstermiştir (Tablo 3). Meyvedeki tohum sayıları ile meyve ağırlığı arasında pozitif bir ilişki olduğu Eltez (1983) tarafindan bildirilmiştir. Çalışmamızda tohum sayıları ile meyve ağırlığı arasında pozitif bir ilişki bulunamamıştır. $\mathrm{Bu}$ durumun iklim ve bakım koşulları ile ilgili olduğu kanaati oluşmuştur. Ayrıca, Özçağıran ve ark. (2011); bütün tohum taslakları gelişen bir elma meyvesinde 10 tohum bulunması gerektiğini, karpel ve gelişen tohum taslağı sayısına göre tohum miktarının artabileceği veya azabileceğini bildirmişlerdir. Çalışmamızda da her ne kadar tohum sayıları ve meyve ağırlığı arasında pozitif bir ilişki bulunmasa da, normal bir tozlanma ve döllenme sonucu olması gereken sayıya yakın değerler göstermiştir.

Meyve sap uzunluğu bakımından en yüksek değere $35.87 \mathrm{~mm}$ ile Golden Delicious çeşidinde, en düşük değer ise $24.80 \mathrm{~mm}$ ile Braeburn çeşidinde; meyve sap kalınlığı bakımından en yüksek değer
$2.74 \mathrm{~mm}$ ile Red Chief, en düşük değer ise $1.79 \mathrm{~mm}$ ile Golden Delicious çeşidinde tespit edilmiştir (Tablo 3). Öztürk ve Öztürk (2016), meyve sap1 uzunluğunun 21.55 (Jersey Mac)-30.84 mm (Golden Delicious) ve meyve sapı kalınlığının 1.97 mm (Golden Delicious)-3.37 mm (Cooper 7 SB2) arasında değiştiğini; Akçay ve ark. (2009), Marmara Bölgesi'nde yetiştiriciliği yapılan bazı elma çeşitlerinde meyve sap1 uzunluğunun 15.7$36.7 \mathrm{~mm}$, meyve sapı kalınlığının ise 1.9-3.7 mm arasında değişiklik gösterdiğini bildirmişlerdir. Çalışmamızda elde edilen meyve sap uzunluğu ve kalınlığı değerleri çeşit özelliğine göre farklılık göstermekle birlikte diğer çalışmalarla uyumlu bulunmuştur.

Parlaklığı ifade eden ve 0-100 arasında değişen L değeri, en yüksek 78.86 ile Golden Delicious, en düşük L değeri ise 19.50 Red Chief çeşidinde bulunmuştur. Kırmızılık değeri olarak ifade edilen a değeri en yüksek 43,24 Braeburn çeşidinde, en düşük -21.01 Golden Delicious çeşidinde; sarılık değeri olarak ifade edilen b değeri ise en yüksek 51.24 ile Golden Delicious çeşidinde, en düșük b değeri ise 10.10 ile Red Chief çeşidinde tespit edilmiştir (Tablo 3). Baytekin ve Akça (2011), yapmış oldukları çalışmalarında; kırmızı renkli Red Chief çeşidinde a değerini 26.13, sarı renkli Stark Spur Golden çeşidinde ise b değerini 45.98 olarak belirlemişlerdir. Satıcı (2011) Granny Smith elma çeşidinde sırasıyla L, a ve b değerlerini 58.50, -15.57 ve 27.98 olarak, Red Chief çeşidinde ise 25.46, 22.75 ve 7.56 olarak belirlemiştir. Çalışmalardan görüldüğü üzere farklı yerlerde yapılan çalışmalarda meyve renkleri arasında farklılıklar görülmektedir. Bu renk farklılıklarının iklimden kaynaklandığı düşünülmektedir.

\section{Sonuçlar}

$\mathrm{Bu}$ araştırma ile Kırşehir'de yetiştiriciliği yapılan bazı elma çeşitlerinin fenolojik ve pomolojik değerleri incelenerek, ildeki performanslarının belirlenmesi amaçlanmıştır. Elma yetiştiriciliği, ekolojiye uygun çeşit ve anaç seçimi, kültürel uygulamaların (budama, seyreltme, sulama, gübreleme vs.) zamanında ve doğru yapılması ile daha başarılı sonuçlar vermektedir. Yapılan çalışmada fenolojik gözlem ve pomolojik ölçümler değerlendirildiğinde, üzerinde çalışılan MM.106 yarı bodur elma anacı üzerine aşılı Mondial Gala, Red Chief, Golden Delicious, Braeburn ve Granny Smith elma çeşitlerinin tamamının, Kırşehir ekolojik koşullarında yetiştiriciliğinin yapılmasının uygun olduğu ve yeni kurulacak bahçeler için tavsiye edilebileceği kanaatine varılmıştır. 


\section{Teşekkür}

$\mathrm{Bu}$ çalışma; Kırşehir Ahi Evran Üniversitesi, Bilimsel Araştırma Projeleri Koordinasyon Birimi tarafindan "ZRT.A4.18.017" No'lu proje ile desteklenmiştir.

\section{Kaynaklar}

Acar, Ş., 2007. Ünye (Ordu) ve çevresinde yetiştirilen mahalli elma ve armut çeşitlerinin morfolojik ve pomolojik özellikleri. Yüksek lisans tezi (basılmamış), Ordu Üniversitesi Fen Bilimleri Enstitüsü, Ordu.

Akça, Y., Şen, S.M., 1991. Van ve çevresinde yetiştirilen mahalli elma çeşitlerinin morfolojik ve pomolojik özellikleri üzerine bir araştırma. Yüzüncü Yll Üniversitesi Ziraat Fakültesi Dergisi, 1(1): 109-128.

Akçay, M.E., Doğan, A., Burak, M., Yaşasın, A.S., Öz, F., 2009. Bazı elma çeşitlerinin Marmara Bölgesi'nde yapılan adaptasyon çalışmaları. Tarım Bilimleri Araştırma Dergisi, 2(2): 65-71.

Alumur, Ü., 1997. Çoruh Vadisi'nde yetiştirilen bazı elma çeşitlerinin fenolojik, biyolojik ve pomolojik özelliklerinin incelenmesi. Yüksek lisans tezi, Atatürk Üniversitesi Fen Bilimleri Enstitüsü, Erzurum.

Anonim, 2018. TSE Türk Standard1 Elma. (www.resmigazete.gov.tr/eskiler/2007/02/200702193-1.doc), (Erişim tarihi: 15.09.2018).

Anonymous, 2018a. Crops Production Quality. (http://www.fao.org/faostat/en/\#data/QC), (Erişim tarihi: 19.10.2018).

Anonymous, 2018b. Apple Descriptors. In: R. Watkins and R.A. Smith (Eds), Commission of the European Communities, ECSC, EEC, EAEC, Brussels and Luxembourg, IPBGR, Rome. (https://cgspace. cgiar.org/bitstream/handle/10568/72794/Apple_desc riptors_320.pd), (Erişim tarihi: 19.09.2018).

Arıkan, Ş., İpek, M., Pırlak, L., 2015. Konya ekolojik şartlarında bazı elma çeşitlerinin fenolojik ve pomolojik özelliklerinin belirlenmesi. Türk TarımGida ve Teknoloji Dergisi, 3(10): 811-815.

Balta, M.F., Uca, O., 1996. Iğdır'da yetiştirilen önemli yazlık elma çeşitlerinin morfolojik ve pomolojik özellikleri. Yüzüncü Yll Üniversitesi Ziraat Fakültesi Dergisi, 6(1): 87-95.

Balta, M.F., Kaya, T., Kırkaya, H., Karakaya, O., 2015. Kumru (Ordu) Yöresinde yetiştirilen mahalli elma genotiplerinin fenolojik, morfolojik ve pomolojik özellikleri. Gaziosmanpaşa Üniversitesi Ziraat Fakültesi Dergisi, 32(1): 47-56.

Baytekin, S., 2006, Tokat ili Turhal ilçesi ekolojik koşullarında farklı klon anaçları üzerine aşılı bazı elma çeşitlerinin performansları, Yüksek Lisans Tezi, Gaziosmanpaşa Üniversitesi Fen Bilimleri Enstitüsü, Tokat.

Baytekin, S., Akça, Y., 2011. MM.106 anacı üzerindeki bazı elma çeşitlerinin performanslarının belirlenmesi. Yüzüncü Yll Üniversitesi Ziraat Fakültesi Tarım Bilimleri Dergisi, 21(2): 127-133.
Blazec, J., Krelinova, J., 2006. Seven-year orchard performance of eleven new apple cultivars from holovousy in comparison with some commonly grown ones. Horticulturae Science (Prague), 33(4): 131-139.

Bongers, A.J., Risse, L.A., Bas, V.G., 1994. Physical and chemical characteristics of apples in European markets. Hort Technology, 4(3): 290-294.

Burak, M., Öz, F., Bulagay, A.N., 1995. Marmara Bölgesi için ümitvar elma çeşitleri III. Bahçe Dergisi, 24(12): $79-81$.

Ceylan, F.B., 2008. Bodur ve yarı bodur anaçlar üzerine aşılı bazı elma çeşitlerinin Niğde ekolojik şartlarında fenolojik ve pomolojik özelliklerinin tespiti. Yüksek lisans tezi, Selçuk Üniversitesi Fen Bilimleri Enstitüsü, Konya.

Çulha, A.E., 2010. Çorum ekolojik şartlarında M9 anacına aşılı bazı elma çeşitlerinin fenolojik ve pomolojik özelliklerinin tespiti. Yüksek lisans tezi, Selçuk Üniversitesi, Fen Bilimleri Enstitüsü, Konya.

Deell, J.R., Khanizadeh, S., Saad, F., Ferree, D.C., 2001. Factors affecting apple fruit firmness-A review. Journal American Pomological Society, 55(1): 8-27.

Doğru, B., 2012. Çorum ili İskilip ilçesinde yetiştirilen mahalli misket elmalarının fenolojik, morfolojik, pomolojik özelliklerinin belirlenmesi ve moleküler olarak tanımlanması. Yüksek lisans tezi, Ordu Üniversitesi, Fen Bilimleri Enstitüsü, Ordu.

Dousti, S., 2010. Braeburn, Fuji, Gala, Granny Smith, Jonagold ve Top Red elma çeşitlerinin M.9 anac1 üzerindeki genç ağaçların verim ve bazı meyve özelliklerinin yaz ayları düşük nemli karasal iklim koşullarında incelenmesi. Yüksek lisans tezi, Ankara Üniversitesi, Fen Bilimleri Enstitüsü, Ankara.

Eltez, M., 1983. Niğde yöresinde üstün özellikli ve özellikle meyve periyodisitesi göstermeyen Amasya tiplerinin seleksiyonu. Doktora tezi, Çukurova Üniversitesi Fen Bilimleri Enstitüsü, Adana.

Fishcer, M., Fishcer, C., 2002. Pinova apple cultivar. The Compact Fruit Tree, 35(1): 19-20.

Gulino, F., 1986. Refractometric trials on Golden Delicious from alto adige. Horticultural Abstracts, 56: 327.

Güneş, A., 2017. Gülnar yöresinde yetiştirilen elma genotiplerinin morfolojik, fenolojik, pomolojik ve moleküler tanımlanması. Yüksek lisans tezi, Mustafa Kemal Üniversitesi Fen Bilimleri Enstitüsü, Hatay.

Hampson, C.R., Kemp, H., 2003. Characteristics of important commercial apple cultivars. In: D.C. Ferree, I. Warrington (Eds.) Apples: Botany, Production and Uses. Cambridge, MA, USA: CABI Publishing, pp. 61-90.

Hicyakmazer, T., 1996. Pozantı-Kamışlı Vadisinde yetiştirilen ülkemiz önemli elma çeşitlerinin derim zamanlarının saptanması ve soğuk depolarda muhafazası. Yüksek lisans tezi, Çukurova Üniversitesi, Fen Bilimleri Enstitüsü, Adana.

Ishiykawa, M., Suzuki, C., Kitayama, H., Sato, T., Kudo, N., 1991, New apple cultivars "Mellow". Bulletin Aomori Apple Experiment Station, 27: 99-109. 
Karlıdağ, H., Eşitken, A., 2006. Yukarı Çoruh Vadisinde yetiştirilen elma ve armut çeşitlerinin bazı pomolojik özelliklerinin belirlenmesi. Yüzüncü Yll Üniversitesi Ziraat Fakültesi Tarım Bilimleri Dergisi, 16(2): 9396.

Kaynaş, K., Karaçalı, İ., 1990. Study on maturity standarts and storage potential of Granny Smith variety of apples grown in Yalova. Journal Agriculture and Forestry, 14(4): 465-474.

Kazankaya, A., Yonar, Y., Başer, S., Doğan, A., Çelik, F., Yaviç, A., 2009. Erciş ve Muradiye yörelerinde doğal olarak yetişen mahalli elma çeşitlerinin bazı meyve ve ağaç özellikleri. Tarım Bilimleri Araştırma Dergisi, 2(2): 89-94.

Legave, J.M., Farrera, I., Almeras, T., Calleja, M., 2008. Selecting models of apple flowering time and understanding how global warming has had an impact on this trait. Journal of Horticultural Science \& Biotechnology, 83(1): 76-84.

Mataa, M., 2000. Performance of some apple cultivars under tropical zambian conditions. Journal of Horticultural Science \& Biotechnology, 75(3): 346349.

McGuire, R.G., 1992. Reporting of objective color measurements. HortScience, 27(12): 1254-1255.

Oğuz, H.İ., Aşkın, M.A., 1993. Erçiş’te yetişen mahalli elma çeşitlerinin morfolojik ve pomolojik özellikleri üzerine araştırmalar. Yüzüncü Yll Üniversitesi Ziraat Fakültesi Dergisi, 3(2): 281-298.

Özçağıran, R., Ünal, A., Özeker, E., İsfendiyaroğlu, M., 2011. Ilıman İklim Meyve Türleri, Yumuşak Çekirdekli Meyveler. Cilt II, Ege Üniversitesi Ziraat Fakültesi Yayınları No: 556, İzmir.

Özongun, Ş., Dolunay, E.M., Öztürk, G., Pektaş, M., 2014. Eğirdir (Isparta) şartlarında bazı elma çeşitlerinin performansları. Meyve Bilimi Dergisi, 1(2): 21-29.

Öztürk, A., Öztürk, B., 2016. Samsun ekolojisinde yetiştirilen standart bazı elma çeşitlerinin fenolojik ve pomolojik özelliklerinin belirlenmesi. Anadolu Tarım Bilimleri Dergisi, 31(1): 1-8.

Satıc1, F., 2011. Granny Smith ve Red Chief elma çeşitlerinin Aloe vera ile biyomuhafazası. Yüksek lisans tezi. Kahramanmaraş Sütçü İmam Üniversitesi, Fen Bilimleri Enstitüsü. Kahramanmaraş.
Seferoğlu, H.G., Kankaya, A., Ertan, E., Tekintaş, F.E., 2006. Aydın ve yöresinde MM.106 anacı üzerine aşılı bazı elma çeşitlerinin fenolojik ve pomolojik özelliklerinin belirlenmesi. Adnan Menderes Üniversitesi Ziraat Fakültesi Dergisi, 3(2): 31-34.

Soylu, A., Ertürk, Ü., Öztürk, Ö., Mert, C., 2003. MM106 anacı üzerine asılı elma çeşitlerinin Görükle koşullarındaki verim ve kalite özelliklerinin incelenmesi-II. Uludă̆ Üniversitesi Ziraat Fakültesi Dergisi, 17(2): 57-65.

Şen, S.M., Bostan, S.Z., Cangi, R., Kazankaya, A., Oğuz, H.İ., 1992. Ahlat ve çevresinde yetiştirilen mahalli elma çeşitlerinin morfolojik ve pomolojik özellikleri. Yüzüncü Yll Üniversitesi Ziraat Fakültesi Dergisi, 2(2): 53-65.

Şen, F.A., 2008. Ankara ili Gölbaşı ilçesinde M.9 Anacı üzerine aş11 Golden Delicious, Mondial Gala ve Fuji elma çeşitlerinin yıllık, gelişimi, meyve verim ve kalitesi üzerine araştırmalar. Yüksek lisans tezi, Ondokuz Mayıs Üniversitesi Fen Bilimleri Enstitüsü, Samsun.

Şenyurt, M., Kalkışım, Ö., Karadeniz, T., 2015. Gümüşhane yöresinde yetiştirilen bazı standart ve mahalli elma (Malus communis L.) çeşitlerinin pomolojik özellikleri. Akademik Ziraat Dergisi, 4(2): 59-64.

Tustin, D.S., Cashmore, W.M., Bensley, R.B., 2001. Pomological and physiological characteristics of slender pyramid central leader apple (Malus domestica) planting systems grown on intermediate vigour, semi-dwarfing and dwarfing rootstocks. New Zealand Journal of Crop and Horticultural Science, 29: 195-208.

Yurtsever, N., 1984. Deneysel İstatistik Metotları. Köy Hizmetleri Genel Müdürlüğü Yayınları No: 121, Ankara.

Uzundumlu, A.S., Işık, H.B., Işık, N., 2009. Dünya işlenmemiş elma sektörüne genel bir bakış. Tarım Bilimleri Araştırma Dergisi, 2(1): 17-23.

Warmund, R.M., 2004. Vegetative growth and fruiting of "Red Fuji" apple on M9 klones and other dwarfing rootstocks, Journal American Pomological Society, 58(3): 152-156. 